\title{
DESENVOLVIMENTO DE PUfE de GARRAFA PET PARA GERAÇÃo DE TRABALHO E RENDA
}

\section{DEVELOPMENT OF PET BOTTLE POUFFE FOR WORK AND INCOME GENERATION}

\author{
SANTOS, Adriana de Paula Lacerda dos. ${ }^{1}$ \\ SILVA, Silvana Bárbara Gonçalves da. ${ }^{2}$ \\ WAKANO, Ceres Sayury Gozzer ${ }^{3}$ \\ ZIMMERMANN, Elisa Harger ${ }^{4}$
}

Por meio da parceria entre a Universidade Federal do Paraná (UFPR) e a Fundação de Ação Social (FAS) da Prefeitura Municipal de Curitiba, o Grupo de Estudos em Inovação Tecnológica (GESIT) está desenvolvendo o Projeto Produção em Foco. Baseado no Modelo de Desenvolvimento de Produtos - MDP, desenvolvido pela equipe do projeto, está sendo possível desenvolver produtos para os agentes de produção da FAS. Este artigo aborda o processo de desenvolvimento de pufes de garrafas pet, bem como, o seu processo de fabricação e a capacitação dos agentes de produção da FAS. Os resultados do projeto mostram que a estrutura criada para o pufe é altamente resistente e que o pufe tem potencial para gerar trabalho e renda para os agentes de produção visto que o seu custo de fabricação é baixo e o seu preço de venda, baseado em pesquisa de mercado, pode ser elevado.

Palavras-chave: Desenvolvimento de produtos. Pufe de garrafas PET. Geração de Trabalho e renda.

Through a partnership between the Federal University of Parana (UPFR) and the Social Action Foundation (FAS) of the City of Curitiba, the Study Group on Technological Innovation (GESIT) is developing the Project Production in Focus. Based on Product Development Model - MDP, developed by the project team, is being able to develop products for the agents of production of FAS. This article discusses the process of development of PET bottles pouffe, as well as its manufacturing process and the training of agents of production of FAS. The project results show that the structure created for the pouffe is highly durable and it has the potential to generate jobs and income for the agents of production since the manufacturing cost is low and its selling price, based on market research can be high.

Key Words: Product development. PET bottles pouffe. Work and income generation.

\footnotetext{
${ }^{1}$ Professora da pós-graduação em Engenharia de Produção - PPGEP UFPR, Universidade Federal do Paraná, Centro Politécnico - Jardim das Américas, 41 3361-3609, adrianapls@ufpr.br

${ }_{2}^{2}$ Mestranda da pós-graduação em Engenharia de Produção - PPGEP UFPR, Universidade Federal do Paraná, silvana.bgsilva@gmail.com

${ }^{3}$ Graduanda em Design de Produto, Universidade Federal do Paraná, cwakano@gmail.com

4 Graduanda em Engenharia de Produção, Universidade Federal do Paraná, elisaharger@hotmail.com
} 
Através de una alianza entre la Universidad Federal de Paraná (UFPR) y la Fundación de Acción Social (FAS) de la ciudad de Curitiba, el Grupo de Estudio sobre Innovación Tecnológica (Gesit) está desarrollando el proyecto producción en Focus. Basado en el Modelo desarrollo del producto - MDP, desarrollado por el equipo del proyecto, está siendo possibile desarrollar productos para los agentes de producción de FAS. Este artículo aborda el proceso de desarrollo de pouffe de botellas de PET, así como su proceso de fabricación y la formación de agentes de producción de FAS. Los resultados del proyecto muestran que la estructura creada por el pouffe es muy duradero y este producto tiene el potencial para generar empleos e ingresos para los agentes de la producción ya que el costo de fabricación es bajo y su precio de venta, basado en la investigación mercado, pueden ser altos. Palabras clave: Desarrollo de productos. Puf de botellas de PET. Empleo y generación de ingresos.

\section{Introdução}

O órgão da Prefeitura Municipal de Curitiba responsável pela assistência social do município é a Fundação de Ação Social (FAS). Um dos projetos da FAS é o Vitrine Social, o qual tem o objetivo de incluir no mercado de trabalho pessoas que se encontram em vulnerabilidade social a fim de gerar trabalho e renda para as pessoas envolvidas no projeto. Nesse contexto, a Universidade Federal do Paraná, em parceria com a FAS, realiza um Projeto de Extensão chamado Produção em Foco visando o desenvolvimento de novos produtos e a resolução de processos, utilizando matérias primas reutilizáveis ou recicláveis de baixo custo, alta qualidade e que possam ter alto valor de mercado.

Dentre estas matérias primas estudadas destacam-se as garrafas PET utilizadas para fazer diversos produtos, inclusive linha de móveis (SILVA et al, 2010). Muito se fala sobre a importância em investir em uma variedade de produtos como um requisito de estratégia competitiva entre as organizações. Desta forma, Slack, Chambers e Johnston (2002) afirmam que o Desenvolvimento de Produtos (DP), é uma das funções principais dentro de uma empresa, criando produtos mais competitivos para atender a evolução do mercado.

Sendo assim, após reuniões sobre a viabilidade de produção de alguns produtos propostos para os agentes de produção da FAS, a equipe do projeto decidiu desenvolver pufes de garrafas PET utilizando o resíduo de uma tela plástica como fixação das garrafas. Essa tela é produzida pela empresa BHS, parceira do projeto, usada no processo de fabricação de papel. A BHS tem a capacidade de disponibilizar cerca de $200 \mathrm{~kg}$ de tela para a produção dos pufes. 
Apesar do pufe de PET já ser um produto produzido e comercializado informalmente, não se encontraram informações detalhadas e comprovadas sobre a sua resistência. Assim, um dos objetivos desse projeto foi desenvolver a estrutura dos pufes de garrafa PET que possibilite o conforto e segurança do usuário durante o uso do pufe. Neste contexto, este artigo tem o objetivo de apresentar os resultados obtidos para o pufe desenvolvido, bem como, apresentar o processo de fabricação desenvolvido para que os agentes de produção possam produzir e comercializar este produto.

\section{O Desenvolvimento de Produtos}

O Processo de Desenvolvimento de Produtos (PDP) é complexo, pois envolve muitas etapas até chegar ao resultado final. Em muitas empresas, o processo não é aplicado em sua totalidade, pois demanda tempo, o que não vai ao encontro das ideias e ritmo de trabalho dos empresários. De acordo com Borges e Rodrigues (2010), há vários autores que se preocupam com esta superficialidade no Processo de Desenvolvimento de Produto (PDP), afirmando que as medidas preventivas devem ser realizadas numa etapa antes, o Planejamento do Produto. Os autores afirmam também que desde a fase inicial, se deve ter a preocupação com a segurança que os produtos oferecerão aos usuários, por isto é importante estudar um método de desenvolvimento de produtos. Apesar de essa preocupação existir, testes são omitidos para o lançamento do produto ocorrer mais rápido, deixando eventuais necessidades de mudança para caso apareçam falhas do projeto original.

Para Borges e Rodrigues (2010), um item muito importante que deve ser tratado em produto é a segurança. Afirmam que esta deve existir nos momentos usuais do cotidiano, como no caso de manusear e utilizar objetos. Borges e Rodrigues (2010) afirmam que a segurança é a regra básica na concepção de produtos, englobando a questão da confiabilidade das funções técnicas do produto e a redução dos riscos para as pessoas e meio ambiente. Desta forma, os autores expõem a importância de identificar possíveis problemas de segurança nos produtos para permitir a compreensão de como os fatores e circunstâncias interagem com eles. Também é importante avaliar as condições em que os objetos estão sendo utilizados, não apenas com relação aos riscos, mas para que propiciem o desempenho das funções para as quais foram desenvolvidos. 


\subsection{Empreendedorismo}

Para Drucker (2001), o empreendedor é aquele que sabe aproveitar as oportunidades, criando algo que irá gerar valor e que empreender não é apenas abrir um novo negócio, mas sim apresentar algo novo com relação ao mercado, produto ou outro quesito.

Entretanto, não se pode mais tratar o empreendedorismo sob uma visão apenas voltada ao mundo dos negócios. O termo já conquistou uma abrangência tal, que pode ser dividida em quatro tipos: Empreendedorismo social, de negócios, governamental e intraempreendedorismo. Neste trabalho tem-se enfoque no empreendedorismo social.

De acordo com Melo Neto e Froes (2004), na última década do século XX se define uma nova modalidade de empreendedorismo, o chamado empreendedorismo social. Estes autores afirmam que este tipo de empreendedorismo se difere do de negócios por dois aspectos principais: não produz bens e serviços para vender, mas para solucionar problemas sociais; e não é direcionado para mercados, mas para segmentos populacionais em situação de risco social, como pobreza, miséria, risco de vida e exclusão social.

Mas aqui se torna relevante a colocação de que os bens e serviços somente podem ser produzidos para vender se for para contribuir com a criação de oportunidades para pessoas com vulnerabilidade social, como é o caso deste projeto de extensão.

Segundo as informações dos autores citados, pode-se afirmar que o empreendedorismo social é também o conjunto de iniciativas implementadas por segmentos sociais excluídos, organizações, comunidades e instituições públicas em busca de novas possibilidades de inserção para grupos sociais menos favorecidos (ALBAGLI e MACIEL, 2003).

O avanço do empreendedorismo social anuncia uma progressão social, econômica e melhoria do ambiente, por meio das técnicas de gestão que irá conduzir para as melhorias futuras.

\section{Metodologia de Pesquisa}

O método de pesquisa adotado para o desenvolvimento do projeto Produção em Foco foi o pesquisa-ação. A pesquisa-ação compreende uma rotina composta por três ações principais: observar, para reunir informações e construir um cenário; 
pensar, para explorar, analisar e interpretar os fatos; e agir, implementando e avaliando as ações. Dentro desta mesma ideia, pode-se dividir o processo de pesquisa-ação em quatro principais etapas, que serão descritas a seguir: fase exploratória, fase principal, fase de ação e fase de avaliação (THIOLLENT, 1997). Esta proposição de divisão em quatro etapas foi adotada para a realização do projeto.

- Fase Exploratória: realização do diagnóstico da situação e das necessidades dos grupos, formação de equipes envolvendo pesquisadores e clientes, divulgação dessas propostas e obtenção do comprometimento dos participantes e interessados;

- Fase principal ou Diagnóstico: no momento em que há um claro diagnóstico sobre a realidade que se deseja pesquisar, os pesquisadores iniciam 0 planejamento da ação;

- Fase de Ação: difusão de resultados, definição de objetivos alcançáveis por meio de ações concretas, apresentação de propostas a serem negociadas entre as partes interessadas e implementação de ações-piloto que posteriormente, após avaliação, poderão ser assumidas pelos atores sem a atuação dos pesquisadores;

- Fase de Avaliação: verificação dos resultados das ações no contexto organizacional da pesquisa e suas consequências a curto e médio prazo e extração de ensinamentos que serão úteis para continuar a experiência e aplicála em estudos futuros.

Outro aspecto que deve ser considerado na utilização da pesquisa-ação é a possibilidade dela fazer parte da articulação produtiva dos recursos existentes em determinados grupos sociais (NOVAES e GIL, 2009).

Para desenvolvimento do pufe foi utilizado o modelo de desenvolvimento de produtos (MDP). Este modelo foi desenvolvido pela equipe do projeto Produção em Foco e divide o processo de desenvolvimento de produtos em três macrofases: PréDesenvolvimento, Desenvolvimento e Pós-Desenvolvimento (SILVA, 2012). Esta divisão permite detalhar melhor as fases pertencentes a cada uma delas, e por se tratar de um processo, ordena melhor as atividades a serem realizadas.

A macrofase de Pré-Desenvolvimento engloba o esclarecimento da tarefa e pesquisa com materiais e tecnologias em nível de planejamento estratégico. $\mathrm{O}$ produto será efetivamente desenvolvido na segunda macrofase, desde a definição 
do escopo e do perfil do público alvo, até análise do processo de fabricação, embalagens e comercialização. Por fim, no Pós-Desenvolvimento, existe o acompanhamento do produto e do processo e análise do ciclo de vida do mesmo.

O desenvolvimento dos pufes está na macrofase de Desenvolvimento, na etapa de Validação do Produto, conforme ilustra a Figura 1. Dessa forma, o pufe já passou pela macrofase de Pré-Desenvolvimento, na qual foram realizados 0 Esclarecimento da Tarefa e o Planejamento Estratégico. Depois, se passou para o Projeto Conceitual, o Projeto Preliminar, o Projeto Detalhado, o Processo de Fabricação e Manutenção e a Elaboração do Protótipo da macrofase de Desenvolvimento. Ainda falta concluir a Validação do Produto e o Lançamento do Produto. Após essas atividades começa o Pós-Desenvolvimento com o Acompanhamento do Produto e Processo, a Engenharia Reversa e a Finalização do Suporte ao Produto. Cabe salientar que algumas atividades das etapas anteriores ainda não foram totalmente concluídas porque o Modelo MDP prevê o avanço das etapas em forma de espiral, isto é, é possível iniciar uma etapa e depois retornar a etapa anterior.

Figura 1 - O Modelo MDP: suas fases e etapas

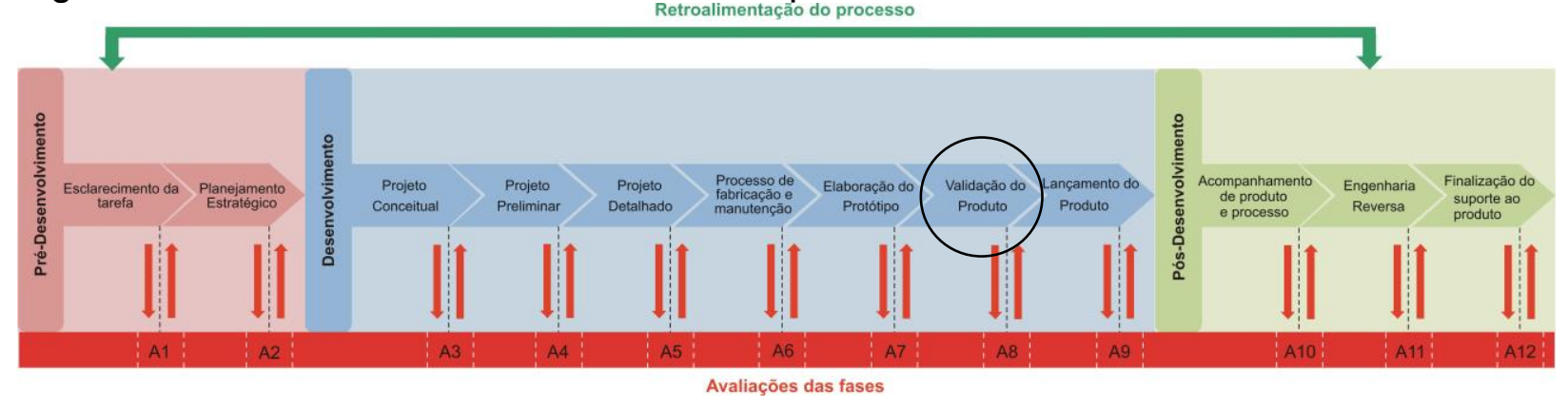

Fonte: As autoras

\section{O Pufe}

Foram desenvolvidos quatro modelos de pufes (Figura 2), sendo dois quadrados, mas utilizam garrafas diferentes. Todos eles são formados por módulos e possuem o mesmo sistema de fabricação. As garrafas utilizadas necessitam serem todas do mesmo modelo (marca, capacidade), ou compatíveis, de modo que seja possível construir um módulo. 
Figura 2 - Modelos de pufes desenvolvidos pela equipe do Projeto

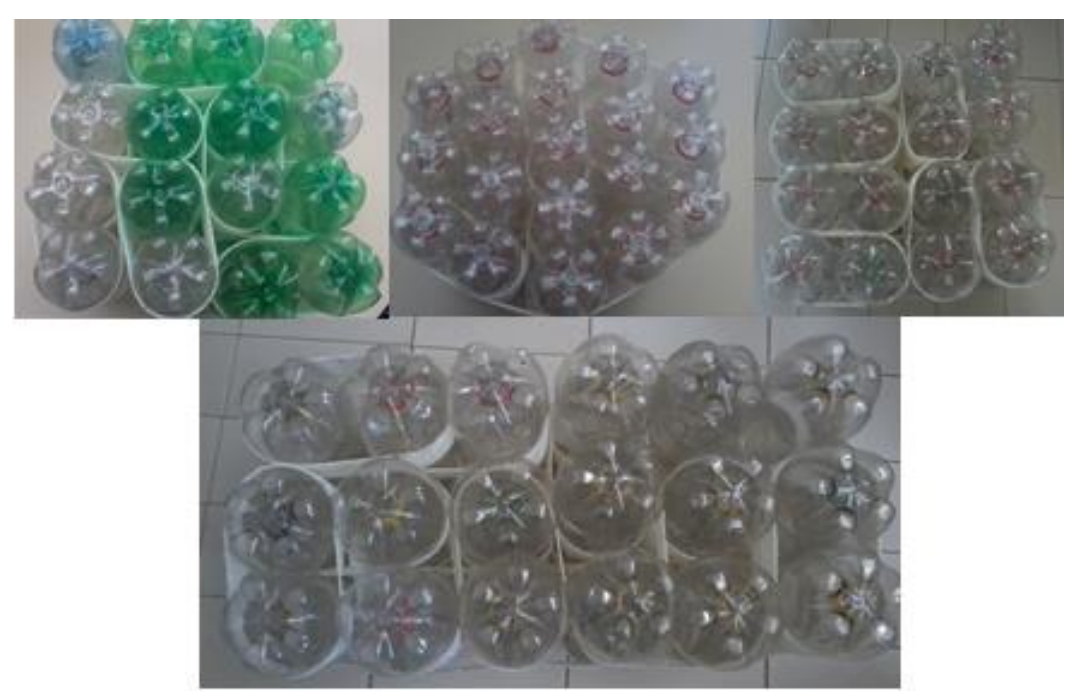

Fonte: As autoras

Para cada tipo de pufe foram construídos três protótipos os quais foram levados para o laboratório para testes mecânicos.

Para o teste de carga foram desenvolvidas três formas de união dos módulos. A primeira união foi realizada com fita adesiva Silvertape, a qual tem poder adesivo e resistência maior que as fitas adesivas comuns, devido às fibras de tecido na sua composição, que ajudam a fixar melhor os módulos, deixando-os mais estáticos entre si. Os módulos foram unidos dois a dois e, então, presos um ao outro de modo a formar um pufe com formato aproximadamente quadrangular.

A segunda e terceira forma de união foi feita com a tela secadora da BHS. Essa tela foi cortada e presa de duas formas: em um dos pufes, as telas foram unidas através de um pino entre as suas tramas (Figura 3); em outro pufe, as telas foram unidas por meio da costura das suas extremidades com fio de nylon (Figura 4). As telas foram produzidas para unir os módulos dois a dois. Assim, foram utilizados vários invólucros de tela para formar o pufe de 16 módulos. Comparada a fita adesiva, a tela secadora prende mais firmemente os módulos de garrafa PET e, com o tempo, não perde seu poder de fixação, como o que ocorre com a fita adesiva. 


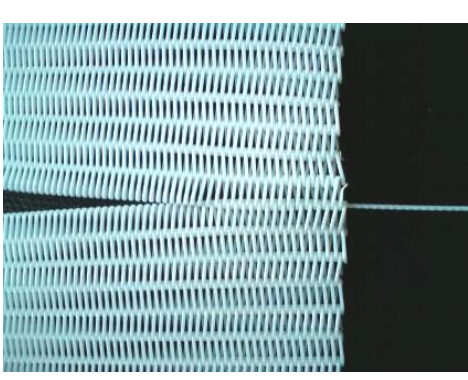

Fonte: As autoras

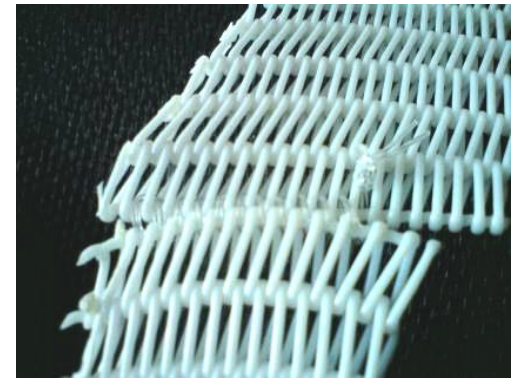

Fonte: As autoras

Para o ensaio de resistência da estrutura dos pufes de garrafa PET, foram utilizados 3 pufes, unidos de 3 formas diferentes, já descritas anteriormente. $O$ ensaio ocorreu dia 4 de maio de 2011, no Laboratório de Materiais e Estruturas (LAME). A prensa utilizada foi a WPM modelo 2D100 de carga máxima de 100 toneladasforça (última calibração em 16 de junho de 2010 pela Dinateste Indústria e Comércio Ltda., certificado número 500c/10).

A escala utilizada foi com carga máxima de 10 tonf, sendo, portanto, cada ponto da escala correspondente a $50 \mathrm{kgf}$. Os resultados obtidos estão representados na tabela 1.

Tabela 1 - Resultados do ensaio mecânico com pufes

\begin{tabular}{|l|r|}
\hline \multicolumn{1}{|c|}{ Pufe } & Carga suportada (kgf) \\
\hline Tela presa com pino & 324,35 \\
\hline Tela costurada com nylon & 374,35 \\
\hline Fita adesiva Silver Tape & 399,35 \\
\hline
\end{tabular}

Fonte: As autoras.

Como se pode observar, todos os pufes suportaram mais de $300 \mathrm{kgf}$, número significativo quando comparado a produtos similares do mercado que suportam cerca de $160 \mathrm{kgf}$ (MAGAZINE LUIZA, 2011).

Baseando-se nos ensaios realizados, a equipe do Projeto Produção em Foco selecionou o pufe com a tela costurada com nylon para ser desenvolvido, visto seu baixo custo e facilidade de produção. 
No dia 20 de setembro de 2011 foram realizados mais oito ensaios de pufes no mesmo laboratório, com a presa WPM modelo 2D100 (agora com calibração em 26 de maio de 2011 pela mesma empresa - Dinateste -, certificado número $566 \mathrm{c} / 11)$.

Nestes ensaios priorizou-se conhecer o comportamento dos pufes dentro de algumas variáveis, como diferentes tamanhos de garrafa Coca-Cola, utilização de tampa nas garrafas, módulo diferente com garrafa de Pepsi/Guaraná/Soda/Sukita e Cini/Wimi e utilização de um número mínimo de telas secadoras. A descrição detalhada de cada pufe bem como cada resultado individual encontra-se no Apêndice A.

Os resultados mostraram que as garrafas de Coca-Cola, independente do tamanho, possuem uma resistência similar: aproximadamente $350 \mathrm{kgf}$. Entretanto, quando tampadas, esta resistência aumenta, sendo de aproximadamente $550 \mathrm{kgf}$.

Quanto ao uso de um módulo diferente, que consiste na união de somente 2 garrafas de Pepsi/Guaraná/Soda/Sukita e Cini/Wimi, o pufe resistiu em média 222,5 kgf, sendo considerável viável a comercialização.

Por fim, constatou-se que é possível utilizar um número mínimo de telas secadoras para prender os módulos, apenas para garantir que estejam todos conectados, pois se notou que as telas têm como maior função prender os módulos juntos (o número mínimo depende do formato do pufe, por exemplo: o pufe de coca cola de 2 litros de dezesseis módulos necessita de 24 telas). A resistência ao peso é garantida pelas garrafas. A estabilidade do pufe é conseguida com a utilização de telas que prendem ao redor de todos os módulos, juntamente com a utilização de um papelão ondulado e uma chapa de madeira, ambos presos com a tela em sentido perpendicular. Também foram realizados testes com essa configuração, apresentados no Apêndice A.

Ressalta-se que durante os ensaios, em nenhum dos casos ocorreu a ruptura, mas sim deformação na garrafa, a qual ficou consideravelmente amassada. Este fenômeno ocorreu para dentro da garrafa, pois tanto as telas, quanto as fitas, não permitiam movimento externo.

A maciez do pufe será garantida pela espuma colada na sua lateral (figura 5) e na parte superior. Esta espuma é resíduo do processo de fabricação de colchões, sendo de fácil obtenção. $O$ revestimento do pufe será feito de crochê, amarradinho ou tecelagem. A Figura 6 mostra um exemplo em crochê. 
Figura 5 - Pufe com as telas e a espuma

Figura 6 - Exemplo de revestimento do Pufe

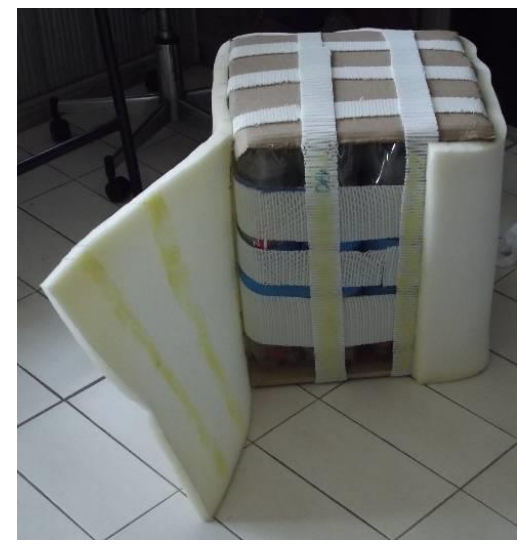

Fonte: as autoras.

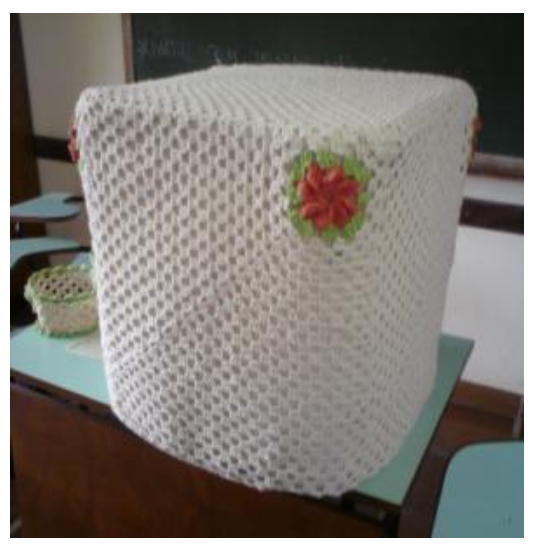

Fonte: as autoras.

\section{Estudo detalhado do processo de fabricação do pufe}

Foi elaborado um procedimento padrão para o processo de fabricação dos pufes a fim de facilitar a montagem dos pufes pelos agentes de produção da FAS. Este procedimento apresenta um esquema detalhado de montagem a fim de garantir que todos os produtos serão iguais. A Figura 7 apresenta a ficha de fabricação utilizada para a confecção do pufe. 
Figura 7 - Ficha de fabricação.

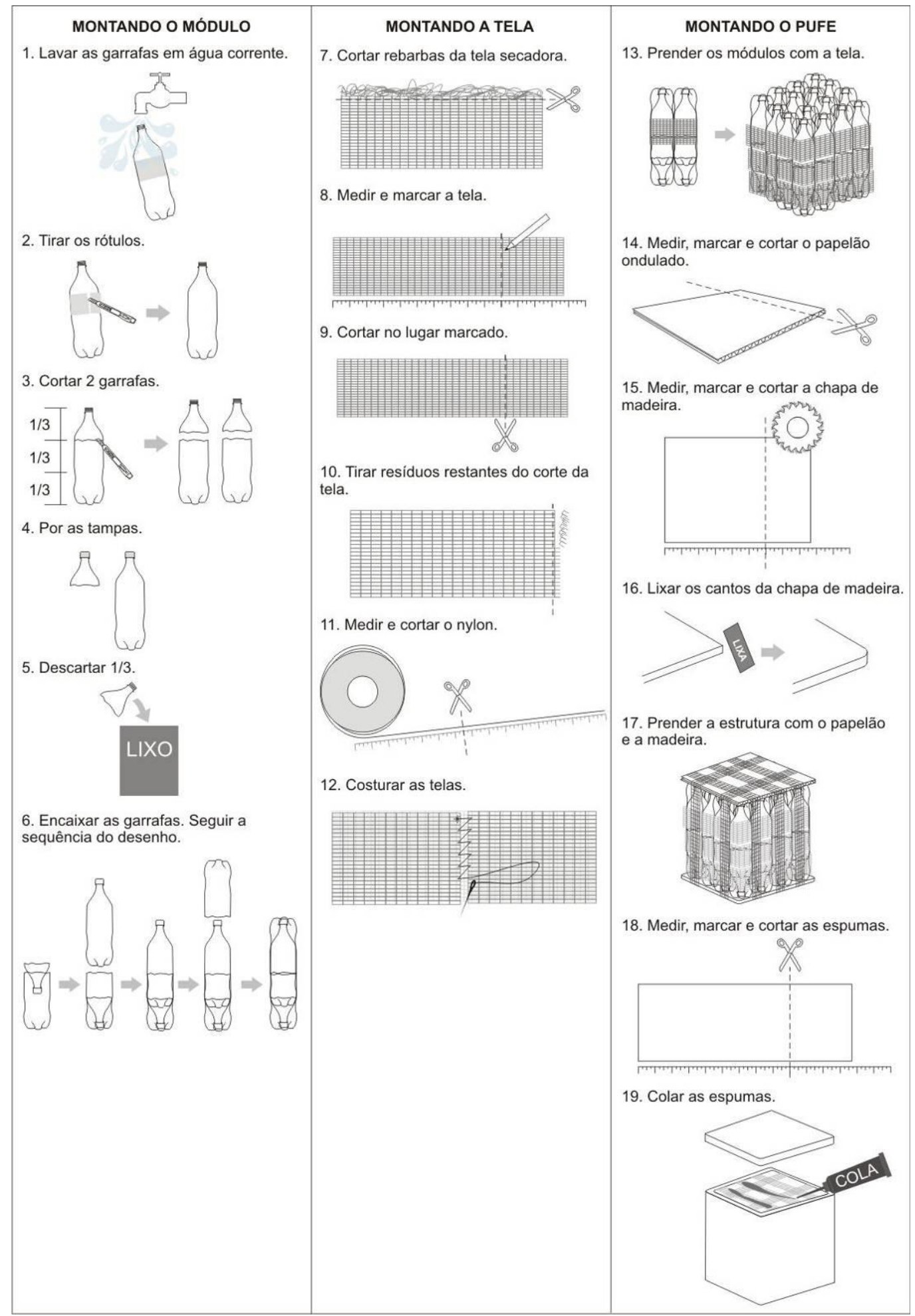

Fonte: as autoras.

O procedimento também explica cada uma das fases de produção do produto haja vista que o agente de produção não pode ter dúvidas no momento da 
confecção das peças. Assim, a figura mostra em desenhos e texto todos os procedimentos para a montagem do módulo, para a montagem da tela e para a união dos dois, montando-se o pufe.

O tempo aproximado para a fabricação de um pufe é de 6 horas, considerando-se todas as atividades serem realizadas por uma única pessoa. Ressalta-se que muitas atividades podem ser realizadas paralelamente, como mostra a Figura 8 , sendo as atividades numeradas de acordo com a ficha de fabricação.

Figura 8 - Fluxograma representado o processo produtivo do pufe

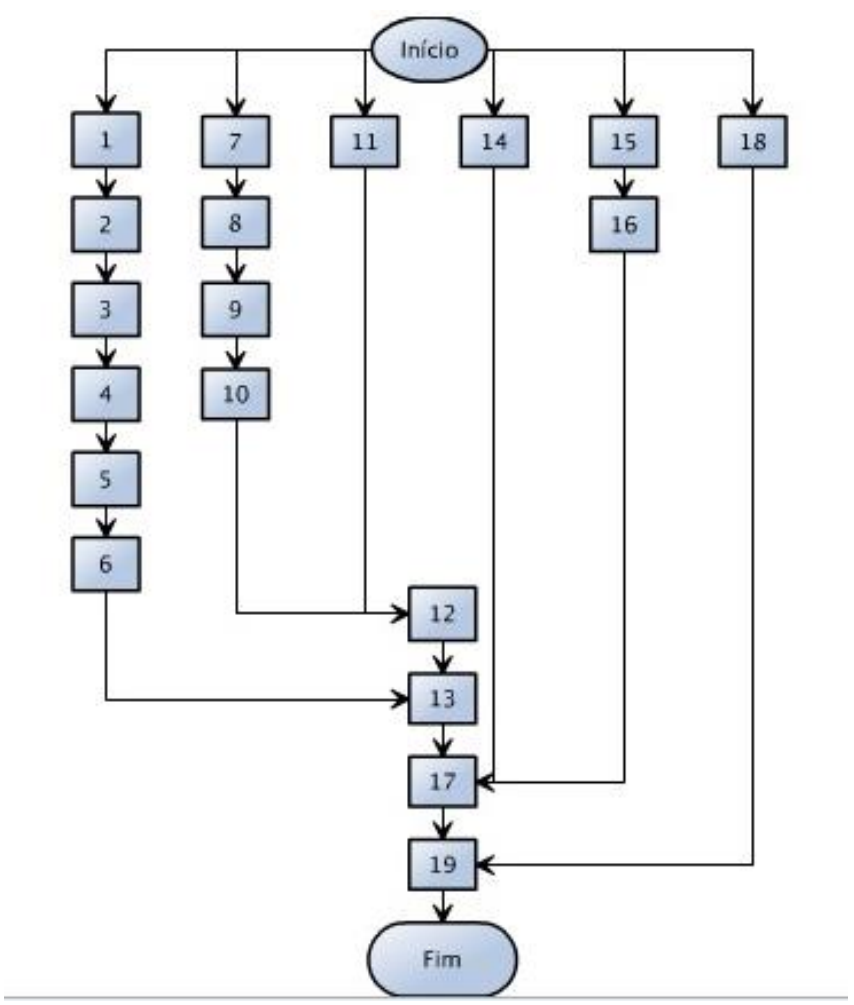

Fonte: as autoras.

Para um pufe quadrado, são necessários 16 módulos, totalizando 48 garrafas. Recomenda-se o uso de luvas durante toda a montagem do pufe.

O custo de produção previsto para a estrutura do pufe será de $R \$ 33,00$, aproximadamente $R \$ 13,00$ para compra de materiais e $R \$ 20,00$ para pagamento da mão-de-obra. A pesquisa de mercado realizada pela equipe do projeto mostrou que este pufe poderá ser comercializado por aproximadamente $R \$ 100,00$ (Wakano, Zimmerman, 2011). O custo dos materiais de produção encontra-se na tabela 2. 
Ressalta-se que não estão inclusos os custos indiretos de fabricação tais como aluguel, equipamentos, dentre outros.

Tabela 2 - Custo dos materiais de produção

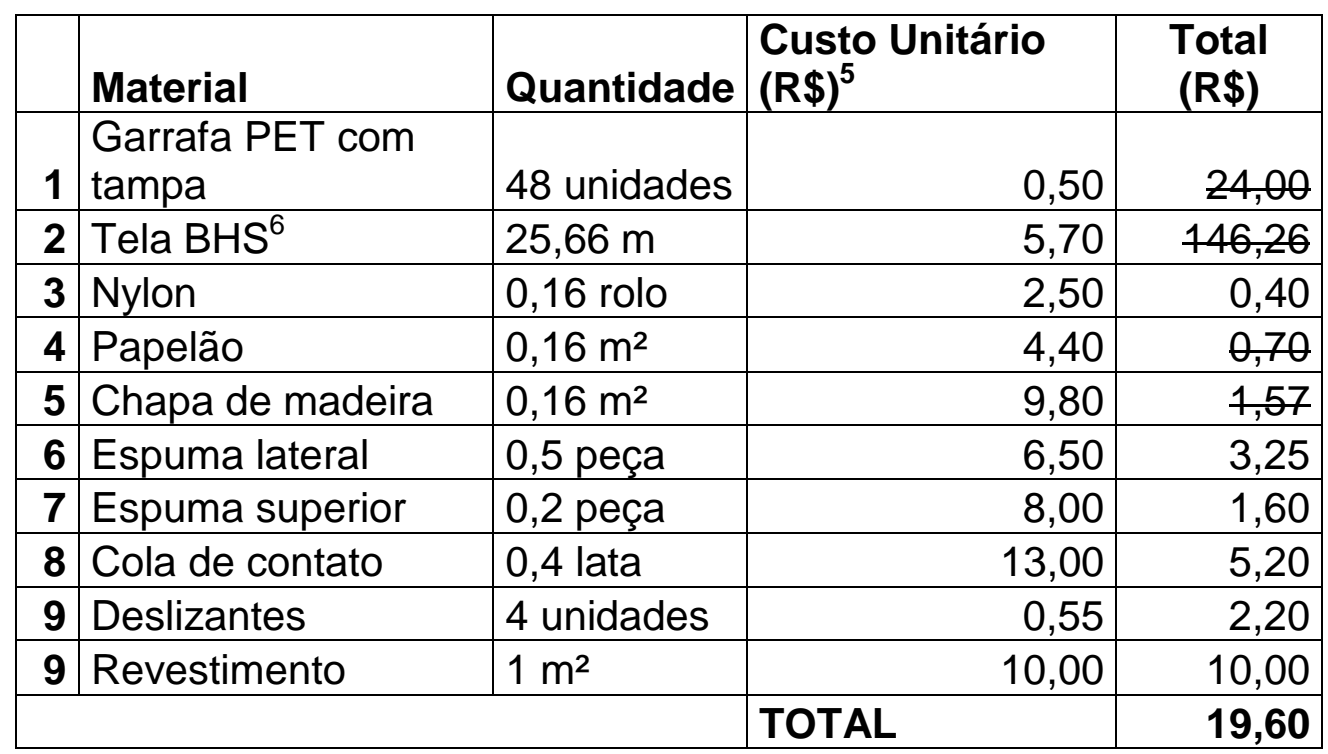

Fonte: As autoras.

Apesar de alguns materiais apresentarem valor comercial, eles foram adquiridos gratuitamente através do descarte, como é o caso das garrafas PET, da tela BHS, do papelão e da chapa de madeira. Na tabela foram descritos seus valores comerciais para comparação. Assim, sem contabilizá-los, o custo total de materiais do pufe fica em torno de 20 reais.

\section{A formação dos Agentes de Produção}

Alguns grupos da FAS apresentam potencial para produzirem os pufes desenvolvidos. A ideia é que cada grupo trabalhe o revestimento de forma diferenciada, aplicando os conhecimentos que eles já adquiriam no programa Vitrine Social.

Sendo assim, a equipe do projeto Produção em Foco irá ministrar cursos sistematicamente para ensinar a técnica de fazer pufes. Apesar de a técnica ser

\footnotetext{
${ }^{5}$ Preços pesquisados entre dezembro de 2011 a julho de 2012.

${ }^{6}$ A tela BHS é vendida por $\mathrm{m}^{2}$. Porém, como se obtêm resíduos e o tamanho da largura não é fixo, contabilizou-se a tela por metro linear, dividindo-se o preço do $\mathrm{m}^{2}$ por 20 , para obtenção de tiras de $1 \times 0,05 \mathrm{~m}$, o suficiente para a confecção do pufe.
} 
simples, ela é um pouco longa, portanto serão necessárias oito horas de trabalho. Esse encontro será ministrado pelos participantes do projeto em lugar definido pela FAS.

O curso foi estruturado para atender grupos de 20 pessoas, que serão divididas em grupos de 5 pessoas, totalizando 4 grupos. Cada grupo será responsável por fazer um pufe.

Os principais materiais para a confecção dos pufes são as garrafas PET, as telas, fio de nylon, o papelão ondulado, a chapa de madeira e as espumas. Devido ao grande número de garrafas necessárias para a produção do pufe, parte da coleta delas serão requisitada aos agentes de produção. Esse pedido será realizado previamente a execução do curso, o que já sensibiliza os futuros participantes. As telas serão fornecidas pela empresa BHS e serão levadas pelos participantes do projeto Produção em Foco. A chapa de madeira será fornecida pela FAS, a qual já possui doador desse resíduo. O papelão ondulado será, inicialmente, obtido em descarte de caixas. Entretanto, pretende-se realizar uma parceria futura com o projeto Eco-cidadão, que trabalha com catadores de papel. A espuma é, atualmente, comprada. Como este material é um resíduo da indústria de colchões, seu preço é bem acessível assim como o fio de nylon.

Para a realização do curso serão necessários alguns equipamentos e ferramentas simples (tesouras, estiletes, luvas, agulhas, etc), as quais serão disponibilizadas pela FAS.

Como o curso é ativo, foi previsto a utilização de dinâmicas. $O$ objetivo é que os agentes de produção sintam-se à vontade e compreendam bem as etapas de produção. $O$ encontro foi estruturado da seguinte forma:

Primeiramente será feita uma apresentação de todos os participantes, do conteúdo e dos objetivos propostos para o curso. Após esse primeiro contato, será realizada uma dinâmica visando enfatizar que o objetivo do curso é trocar experiências e que a equipe da UFPR não pretende levar o conhecimento pronto.

Inicialmente, serão mostradas as etapas de confecção dos módulos, corte e costura das telas e montagem da estrutura do pufe. Aproveitando que o grupo já estará descontraído será dada seqüência aos outros passos de confecção, englobando marcação e corte do papelão e das espumas e montagem do pufe final, com telas e a espuma. 
Ao final do curso, todos os participantes avaliarão a montagem do pufe e as suas opiniões serão consideradas para aperfeiçoar a produção do pufe. Os pufes produzidos ficarão com os agentes para desenvolverem 0 revestimento $e$ acabamento.

Na sequência, a equipe do Projeto Produção em Foco auxiliará os grupos na confecção dos pufes por meio de visitas ao local de fabricação e comercialização dos produtos.

\section{Conclusão}

A viabilidade de fabricação e comercialização dos pufes pelos agentes de produção já foram aprovados pela equipe do Projeto Produção em Foco incluindo a FAS.

Atualmente, vários grupos já estão sendo visitados pelos pesquisadores do Projeto e pufes-testes estão sendo enviados a eles para realizarem o acabamento. A próxima etapa do projeto será o lançamento do produto no mercado. Para tanto, a equipe do projeto desenvolverá um projeto com as escolas públicas para coletar sistematicamente as garrafas.

Baseado na pesquisa de mercado desenvolvida pode-se afirmar que o pufe de garrafas pet desenvolvido pela equipe do projeto Produção em Foco irá gerar trabalho e renda para aproximadamente trinta famílias apoiadas pela FAS. Para tanto, será necessário monitorar o processo de fabricação e comercialização destes produtos para eliminar as atividades que não agregam valor e também para identificar formas de aumentar o valor agregado a este produto.

\section{REFERÊNCIAS}

ALBAGLI, S.; MACIEL, M. L. Capital social e desenvolvimento local. In: LASTRES, H. M. M.; CASSIOLATO, J. E.; MACIEL, M. M. (Org.). Pequena empresa: cooperação e desenvolvimento local. Rio de Janeiro: Resume Dumará, 2003.

BORGES, F.M. RODRIGUES, C.L.P. Adaptação da metodologia de Baxter para o planejamento de novos produtos à luz da segurança do trabalho. XIII SIMPEP - São Paulo. Disponível em: http://www.simpep.feb.unesp.br/anais/anais_13/artigos/1119.pdf. Acesso em: 23 ago. 2010. 
BORGES, F.M., RODRIGUES, C.L.P. Pontos passíveis de melhoria no método de projeto de produto de Pahl e Beitz. Revista Gestão e Produção, v. 17, n. 2, p. 271 281, 2010. Disponível em: <http://www.scielo.br/pdf/gp/v17n2/a05v17n2.pdf>. Acesso em: 22 ago. 2010.

CLARK, K. B.; WHEELWRIGHT, S. C.. Managing new product and process development: text and cases. New York: Free Press. 1993.

DRUCKER, P.F. O Advento da nova organização In: HARVARD BUSINESS REVIEW. Gestão do Conhecimento, 2 ed. São Paulo: Campus, 2001.

MAGAZINE LUIZA. Puff Klaus. Disponível em: <http://www.magazineluiza.com.br/produto/index_Produto.asp?Produto=2007471\&lin ha=MO\&Setor=PUFF\&modelo=00 $>$. Acesso em: 18/05/2011

MELO NETO, F. P.; FROES, C. Empreendedorismo social: a transição para a sociedade sustentável. Rio de Janeiro: Qualitymark, 2004.

NOVAES, M.B.C. de.; GIL, A.C. A pesquisa-ação participante como estratégica metodológica para o estudo do empreendedorismo social em administração de empresas. Revista de Administração Mackenzie. São Paulo, v.10, n.1, p. 134-160, 2009 . Disponível em: $<$ http://www.doaj.org/doaj?func=openurl\&genre=journal\&issn=15186776\&volume=10 \&issue $=1$ \&date $=2009$ \&uilanguage $=e n>$. Acesso em: 11 mai. 2011.

ROBSON, C. Real world research: a resource for social scientists and practitioner researchers. Oxford: Blackwell Publishers, 2nd ed., 2002.

SANTOS, A.P.L.; SILVA, S.B.G. Modelo de gestão em desenvolvimento e produção de produtos em projetos sociais - um estudo de caso. Anais. Tercera Conferencia Iboamericana de Ingeniería e Innovación Tecnológica: CIIT, 2011.

SILVA et. al. Ecodesign e consumo: pesquisa sobre o mercado para mobiliários em garrafas PET recolhidas. Ingepro. Santa Maria, v.2, n.4, abr. 2010. Disponível em: <http://ojs.ingepro.com.br/index.php/ingepro/article/view/220/191>. Acesso em: 26 ago. 2011. 
SILVA, S. B. G. Modelo de desenvolvimento de produtos em projetos com foco social. Dissertação (Mestrado em Engenharia de Produção) - Universidade Federal do Paraná, Curitiba, 2012.

SLACK, Nigal; CHAMBERS, Stuart; JOHNSTON, Robert. Administração da Produção. 2 ed. São Paulo: Atlas 2002.

THIOLLENT, M. Pesquisa-Ação nas Organizações. 8.ed. São Paulo: Editora Atlas, 1998. 


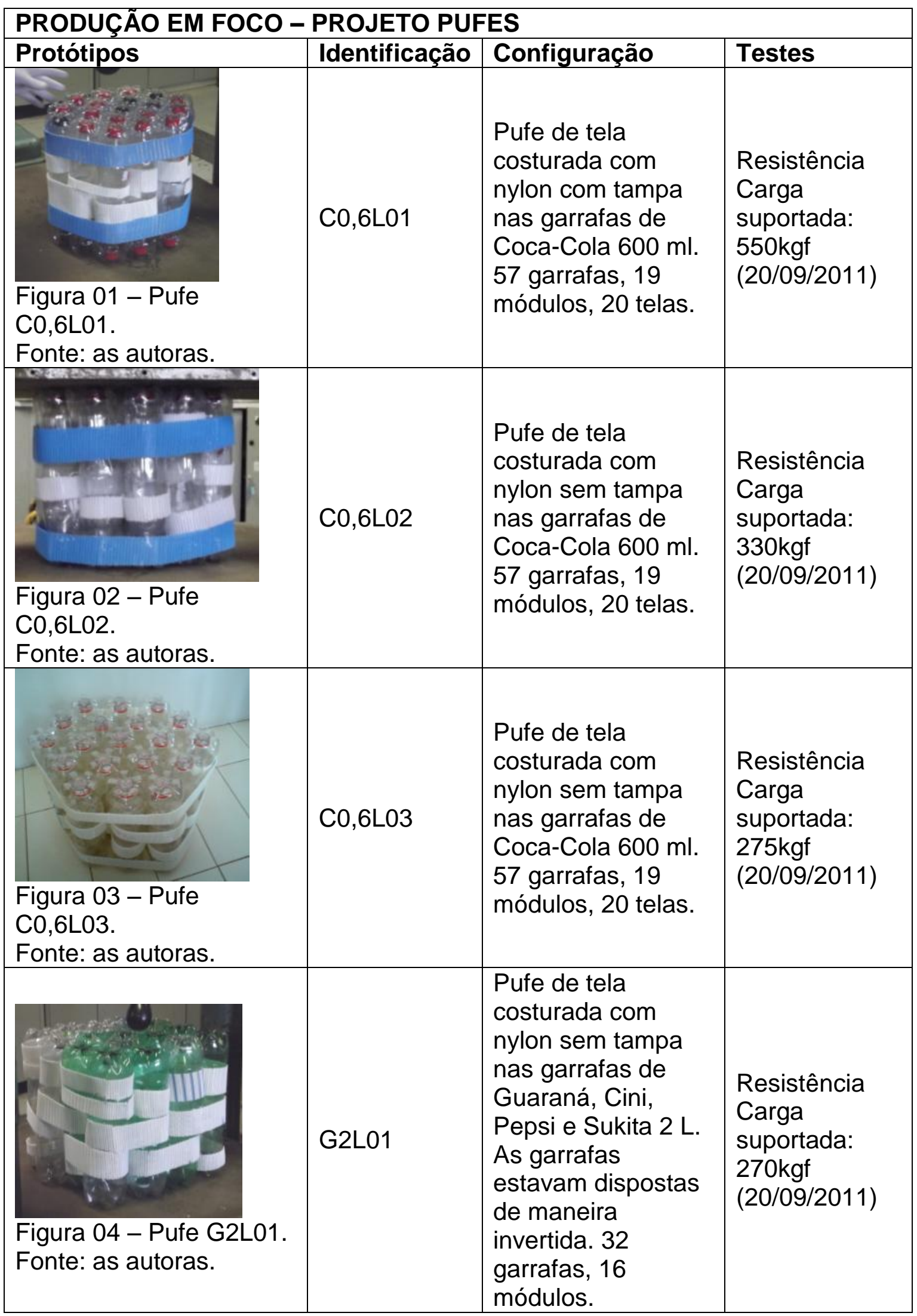




\begin{tabular}{|c|c|c|c|}
\hline $\begin{array}{l}\text { Figura } 05 \text { - Pufe G2L02. } \\
\text { Fonte: as autoras. }\end{array}$ & G2L02 & $\begin{array}{l}\text { Pufe de tela } \\
\text { costurada com } \\
\text { nylon sem tampa } \\
\text { nas garrafas de } \\
\text { Guaraná, Cini, } \\
\text { Pepsi e Sukita } 2 \text { L. } \\
\text { As garrafas } \\
\text { estavam dispostas } \\
\text { no mesmo sentido. } \\
32 \text { garrafas, } 16 \\
\text { módulos. }\end{array}$ & $\begin{array}{l}\text { Resistência } \\
\text { Carga } \\
\text { suportada: } \\
175 \mathrm{kgf} \\
(20 / 09 / 2011)\end{array}$ \\
\hline $\begin{array}{l}\text { Figura } 06 \text { - Pufe } \\
\text { C2,5L01 } \\
\text { Fonte: as autoras. }\end{array}$ & C2,5L01 & $\begin{array}{l}\text { Pufe de tela } \\
\text { costurada com } \\
\text { nylon sem tampa } \\
\text { nas garrafas de } \\
\text { Coca-Cola } 2,5 \mathrm{~L} \text {. } \\
54 \text { garrafas, } 18 \\
\text { módulos, } 27 \text { telas. }\end{array}$ & $\begin{array}{l}\text { Resistência } \\
\text { Carga } \\
\text { suportada: } \\
325 \mathrm{kgf} \\
(20 / 09 / 2011)\end{array}$ \\
\hline $\begin{array}{l}\text { Figura } 07 \text { - Pufe } \\
\text { C2,5L02 } \\
\text { Fonte: as autoras. }\end{array}$ & C2,5L02 & $\begin{array}{l}\text { Pufe de tela com } \\
\text { costura espaçada } \\
\text { de nylon sem } \\
\text { tampa nas garrafas } \\
\text { de Coca-Cola } 2,5 \\
\text { L. } 54 \text { garrafas, } 18 \\
\text { módulos, } 27 \text { telas. }\end{array}$ & $\begin{array}{l}\text { Resistência } \\
\text { Carga } \\
\text { suportada: } \\
375 \mathrm{kgf} \\
\text { Não houve } \\
\text { ruptura das } \\
\text { telas. } \\
(20 / 09 / 2011)\end{array}$ \\
\hline $\begin{array}{l}\text { Figura } 08 \text { - Pufe C2L04 } \\
\text { Fonte: as autoras. }\end{array}$ & C2L04 & $\begin{array}{l}\text { Pufe de tela } \\
\text { costurada com } \\
\text { nylon sem tampa } \\
\text { nas garrafas de } \\
\text { Coca-Cola } 2 \text { L. } 48 \\
\text { garrafas, } 16 \\
\text { módulos, } 24 \text { telas. } \\
\text { Construído sem a } \\
\text { utilização de poka- } \\
\text { yoke. }\end{array}$ & $\begin{array}{l}\text { Resistência } \\
\text { Carga } \\
\text { suportada: } \\
\text { 350kgf } \\
\text { O poka-yoke } \\
\text { se mostrou } \\
\text { indiferente nos } \\
\text { resultados. } \\
\text { (20/09/2011) }\end{array}$ \\
\hline$\gamma$ & C2L05 & $\begin{array}{l}\text { Pufe de tela } \\
\text { costurada com } \\
\text { nylon com tampa } \\
\text { nas garrafas de } \\
\text { Coca-Cola } 2 \text { L. } 48 \\
\text { garrafas, } 16 \\
\text { módulos, } 32 \text { telas. } \\
\text { Com base de } \\
\text { madeira e } 4\end{array}$ & $\begin{array}{l}\text { Resistência } \\
\text { dos } \\
\text { deslizantes } \\
\text { Carga } \\
\text { suportada: } \\
249,35 \mathrm{kgf} \\
(16 / 11 / 2011)\end{array}$ \\
\hline
\end{tabular}




\begin{tabular}{|c|c|c|c|}
\hline $\begin{array}{l}\text { Figura } 09 \text { - Pufe C2L05 } \\
\text { Fonte: as autoras. }\end{array}$ & & $\begin{array}{l}\text { deslizantes de } \\
\text { plástico. }\end{array}$ & \\
\hline $\begin{array}{l}\text { Figura } 10 \text { - Pufe C2L06 } \\
\text { Fonte: as autoras. }\end{array}$ & C2L06 & $\begin{array}{l}\text { Pufe de tela } \\
\text { costurada com } \\
\text { nylon com tampa } \\
\text { nas garrafas de } \\
\text { Coca-Cola } 2 \text { L. } 48 \\
\text { garrafas, } 16 \\
\text { módulos, } 32 \text { telas. } \\
\text { Com base de } \\
\text { madeira, } 4 \\
\text { deslizantes e } \\
\text { espuma. }\end{array}$ & $\begin{array}{l}\text { Deformação } \\
\text { da estrutura } \\
\text { ao longo do } \\
\text { tempo } \\
\text { Carga: } 98,23 \\
\text { kg } \\
\text { Início: } 43,3 \text { x } \\
43,3 \times 51,4 \mathrm{~cm} \\
\text { Final: } 43,5 \mathrm{x} \\
44 \times 49 \mathrm{~cm} \\
(16 / 11 / 2011 \text { a } \\
20 / 03 / 2012)\end{array}$ \\
\hline
\end{tabular}

